\title{
Vector-borne diseases: Reconciling the debate between climatic and social determinants
}

\author{
Berrang-Ford L ${ }^{1 *}$, Harper $\mathrm{SL}^{2}$, Eckhardt $\mathrm{R}^{3}$
}

\author{
Affiliations \\ ${ }^{1}$ McGill University, Montréal, QC \\ 2 University of Guelph, Guelph, ON \\ ${ }^{3}$ Department of Geography, McGill University, Montréal, QC \\ *Correspondence: lea.berrangford@mcgill.ca
}

Suggested citation: Berrang-Ford L, Harper SL, Eckhardt R. Vector-borne diseases: Reconciling the debate between climatic and social determinants. Can Comm Dis Rep 2016;42:211-2. https://doi.org/10.14745/ccdr.v42i10a09

\section{Background}

We have long recognized the role of climate and environmental change in driving the distribution and incidence of vector-borne diseases (VBDs), both on a global and local scale. VBDs are considered particularly sensitive to climate change due to the importance of climate and weather in determining the life cycle of disease vectors and the transmission potential of pathogens. Many of these important ecological changes and drivers are themselves driven by social change and the distribution of VBDs remains strongly correlated with social determinants.

A debate has arisen within the climate change and health field regarding the importance of climate change vis-à-vis the social determinants of health. This debate-largely attributable to the conceptual and methodological complexity of integrating climate and social determinants into quantitative models-has contributed to perspectives ranging from "there is little evidence that climate change has already favoured infectious disease" (1) to "climate change is potentially the biggest global health threat of the 21 st century" (2). The field of public health is predicated upon evidence-based decision-making. As a result, our inability to appropriately conceptualize and confidently model climate impacts on health in the context of existing social gradients is an important constraint to an effective public health response to climate change.

\section{Objective}

To review our conceptual understanding of how social and climatic variables interact to affect global VBD transmission.

To critically appraise the extent to which existing conceptual approaches and analytic methods in epidemiology have-or have not-successfully integrated social determinants into climate change projections.

To identify challenges and opportunities for improved conceptual and methodological integration of social and climatic determinants of VBDs in a changing climate.

\section{Narrative}

Three key points are presented using case studies. a) The effects of social determinants on VBDs are significant and well-established, yet poorly integrated into climate models. b) Climatic and social determinants interact to affect VBD transmission and manifest at very different scales. It is therefore difficult, not particularly constructive and, in some cases, inappropriate to compare their relative effect on VBD transmission. c) Due to this social modification of climate effects, existing social gradients in health provide intervention entry points for adaptation to predicted climate change impacts on VBDs.

It is not that social determinants matter more than ecological or climatic determinants, but rather that social variables are the proximal drivers that will modify the extent to which climate will impact VBDs globally. Two examples illustrate these points.

The first case assesses the likelihood of autochthonous (locally acquired, mosquito-transmitted) malaria re-emergence in Canada $(3,5)$. Malaria transmission occurred in Canada in the past and southern Ontario has the conditions (the presence of a competent vector, potential for limited but sufficient climatic conditions for parasite replication) for transmission today (3). Specifically, the malarial parasite Plasmodium vivax requires approximately 30 days at $18^{\circ} \mathrm{C}$ or 20 days at $20^{\circ} \mathrm{C}$. Above $33^{\circ} \mathrm{C}$ or below $16^{\circ} \mathrm{C}$, the cycle cannot be completed and transmission will not occur (3). Such conditions already occur in Canada for short periods and in locations with competent mosquito vectors (particularly southern Ontario) and future warming is expected to increase the potential number of cycles and replications. For example, from 1983-2003, there were fewer than 40 consecutive days with a mean daily temperature greater than $18^{\circ} \mathrm{C}$ per year in southern Ontario. By 2070-99, we can expect 90 consecutive days greater than $18^{\circ} \mathrm{C}$ per year in this region, reflecting the potential for three full Plasmodium vivax transmission cycles in Canadian mosquitoes (3). These are underestimates since the parasite does not require consecutive days of heat for transmission. In parallel, increased international travel from malaria-endemic regions and high population densities coincide 
determinants. As effect modifiers of the climate-vector-borne disease relationship, social interventions have the potential to reduce climate impacts on health beyond direct health benefits by reducing climate vulnerability. Social determinants of VBD transmission provide the most feasible and perhaps only realistic, opportunity for VBD control and prevention in a changing climate.

\section{Conflict of interest}

None.

\section{References}

1. Lafferty KD. The ecology of climate change and infectious diseases. Ecology 2009;90:888-900.

2. Costello A, Abbas M, Allen A, Ball S, Bell S, Bellamy R, et al. Managing the health effects of climate change: Lancet and University College London Institute for Global Health Commission. Lancet 2009;373:1693-733.

3. Berrang-Ford L, MacLean JD, Gyorkos TW, Ford JD, Ogden $\mathrm{NH}$. Climate change and malaria in Canada: A systems approach. Interdiscip Perspect Infect Dis 2009;385487.

4. Eckhardt R, Berrang-Ford L, Ross NA, Pillai DR, Buckeridge DL. A spatial analysis of individual- and neighbourhood-level determinants of malaria incidence in adults, Ontario, Canada Emerg Infect Dis 2012; 18:775-82.

5. Eckhardt R. An assessment of imported malaria and the risk of autochthonous transmission in Ontario, Canada. MA thesis, Department of Geography, McGill University, Montréal, Canada 2010.
In the face of negligible international success in reducing climate change emissions, we must adapt to the emerging health impacts of climate change. Intervention on climatic determinants of health is thus an inadequate yet important lever for public health action. We can develop interventions to modify social 